\title{
Deconstructing the Therapeutic Alliance: Reflections on the Underlying Dimensions of the Concept
}

\section{Una Deconstrucción de la Alianza Terapéutica: Reflexiones sobre las Dimensiones Subyacentes del Concepto}

\author{
Mariane Krause \\ Carolina Altimir \\ Pontificia Universidad Católica de Chile, Chile \\ Pontificia Universidad Católica de Chile, Chile \\ Adam Horvath \\ Simon Fraser University, Canada
}

\begin{abstract}
The concept of the alliance has received increasing attention from both clinicians and researchers over the past thirty years. Yet it remains only vaguely defined, and its role and effect in therapy continues to be controversial. The goal of this paper is to clarify the meaning of the concept as it is perceived by clients and therapists, and to compare and contrast these perceptions to the notion of the alliance as it is de-facto implemented in research through the most frequently used alliance measures. Our results indicate that clients and therapists pay attention to different aspects of the relationship when they assess the quality of the alliance. The most frequently used measures share some important features but also exhibit significant differences. Some alliance measures attempt to accommodate the differences in the clients' and therapists' points of view but others ignore them. In general, these popular measures do not appear to be closely matched to the unique client/therapist perspectives. The impact of the substantial variations between measures and the absence of a clear distinction between the differing perspectives of clients and therapists is discussed.

Keywords: concept, therapeutic alliance, therapy.
\end{abstract}

Resumen. El concepto de la alianza terapéutica ha sido objeto de una creciente atención por parte de terapeutas y investigadores en los últimos treinta años. No obstante, aún no se ha llegado a una definición precisa del mismo, y aún no existe consenso sobre su papel y efecto en la terapia. El objetivo de este artículo es clarificar el significado del concepto tal y como lo perciben clientes y terapeutas, y comparar y contrastar estas percepciones con la forma en que se implementa la alianza en la literatura científica a través de las medidas más frecuentes de la alianza. Nuestros resultados indican que, cuando evalúan la calidad de la alianza, los clientes y terapeutas se centran en aspectos diferentes de la relación. Las medidas más empleadas tienen algunas importantes características en común, pero también exhiben diferencias importantes. Algunas medidas de la alianza intentan tener en cuenta las diferencias entre los puntos de vista de clientes y terapeutas, pero otras no. En general, las medidas más populares no parecen adecuarse a las particulares perspectivas cliente/terapeuta. Se aborda el impacto de las variaciones importantes entre medidas, y de la ausencia de una distinción clara entre las perspectivas divergentes de clientes y terapeutas.

Palabras clave: alianza terapéutica, concepto, terapia.

Correspondence concerning this article should be addressed to Mariane Krause, Department of Psychology, Pontificia Universidad Católica de Chile. Vicuña Mackenna 4860, Macul, Santiago de Chile.

E-mail:mkrause@uc.cl 


\section{Introduction}

The concept of the alliance has been the subject of a great deal of attention by both psychotherapy researchers and clinicians (Hatcher, 2010; Horvath et al, 2011a). Over the past 25 years, the number of journal articles focusing on the alliance has increased dramatically. By the end of 2010 over 7,500 publications were listed on the PsycInfo database under the keyword "alliance". Though the sheer number of publications, by itself, does not guarantee the importance of the construct, it does at least suggest that the concept has captured the interest and imagination of a very broad cross section of the therapist community.

Apart from its growing popularity, the concept of the alliance is quite unique in other ways: First, it is a "pan theoretical" variable, not embedded in a specific theoretical framework, nor is it uniquely associated with a specific treatment, technique, or model of how therapy can produce change. The alliance is thought to be a factor in all helping relations but it is not an integral part of a formal theory or logical chain of ideas linked together to account for how psychological growth can occur. Second, the notion of an alliance between therapist and client transcends the traditional distinction between technique and relationship aspects of treatment. From some perspective it is both (technique and relationship) and from a different point of view it is neither (Horvath \& Hatcher, 2009).

Though a vast number of publications are available about the alliance; how it relates to outcome (Martin et al, 2000; Horvath et al, 2011), the therapists' role (Baldwin, Wampold, \& Imel, 2007), its development (Castonguay et al, 2010), and training implications (Hilsenroth et al, 2002), relatively little work has been done to clarify how the alliance is experienced by the participants ${ }^{1}$. Most importantly, the idea of the concept of the alliance has undergone substantial development over the past 30 years but very little work has been done to clarify and document these evolving changes since the pioneering work on the subject by Luborsky (1976) and Bordin (1976-89). In this article we first attempt to map these historical developments and situate the concept of the alliance -as it is currently used-next we summarize some qualitative research to explicate the unique differences and commonalities in clients' and therapists' perspectives on the subject and last, we examine the contents of the most frequently used alliance measures to better understand how these instruments de-facto define the concept in current research use.

\section{What is the alliance?}

We see alliance as a broad and evolving concept. In order to better understand how the notion of alliance between therapist and patient became the concept we currently use, we need to -briefly- review the history of its development: The roots of the idea go back to Freud who, starting in 1913 (Freud, 1913), turned his attention to the question: How does a patient manage to resist the temptation of discontinuing treatment in the face of the rising anxiety provoked by the emergence of unconscious conflicts and transference? He proposed that there was an "unobjectionable or positive transference" at work. The patient was endowing the person of the analyst with positive qualities and attributes; these nurturing attributes were based on patient's past positive experiences with persons of power and authority.

This notion of "positive" or "unobjectionable" transference turned out to be both a troublesome and generative concept. Almost from the beginning some analysts were disturbed by this idea of positive attachment: Is this kind of transference to be analyzed? Interpreted? And how can this non-objectionable transference be distinguished from the patient's over-idealization of the analyst or therapist -which would be considered a resistance maneuver? (Abend, 2000) On the other hand, the idea of a therapeutic "pact" or partnership was extrapolated by Greenson and others (Greenson, 1967) to take account of the client's conscious, active, positive participation in analysis and therapy. The notion of the alliance (also working alliance, therapeutic alliance, helping alliance) continues to be controversial in analytic circles. Most recently analytic theorists advocating a more balanced interpersonal perspective of the relationship in analysis and dynamic therapies have argued that their interpersonal dialec- 
tical understanding of the therapy process obviates need for concepts such as the alliance (Safran \& Muran, 2006).

Historically the important turning point in the development of the alliance construct came in the mid-70s when Lester Luborsky (1976) and Ed Bordin (1976) both proposed a reconceptualization of the alliance. They separated the concept from its roots in positive transference and focused on the conscious "working together" aspect of the therapeutic pact. They argued that the alliance between therapist and client is not unique to psychoanalysis or psychodynamic therapy: it is an important bidirectional process that is ubiquitous in all forms of helping relationships.

While Luborsky's and Bordin's ideas of this generic alliance concept differed in some important detail, they both suggested that the alliance between patient and therapist was not an unconscious projection but a dialectical ego-based process that depended on joint commitments to important aspects of the therapy process as well as a kind of affective or emotional bond between therapist and client. Both of these pioneers of the modern construct of the alliance were informed in their thinking about the subject by psychoanalytic theorists such as Greenson (1965), Stone (1961), and Zetzel (1956). Their understanding and appreciation of the client's sense of commitment and ownership of the joint enterprise of therapy rested also on their work as clinicians. Importantly however, in his seminal chapter Luborsky (1976) focused on the structure of the stage-like development of the alliance while Bordin emphasized some of the early therapy processes such as agreements on the goals of treatment and the therapy tasks plus the development of an interpersonal bond (Bordin, 1976). Rather than providing a concise, narrow definition of what the alliance is, and how it relates to other aspects of the therapeutic relationship or therapy process, they focused on how one might identify the presence of a good alliance and its impact. The likely reason for leaving the construct so open-ended was the idea that the alliance was a common feature of all forms of treatment, and providing a definition would have necessitated the use of language and terminology that would have been acceptable in some parts of the therapeutic community, but not in others.
At the time that this new vision of the alliance was put forward there was a fundamental shift in research emphasis among psychotherapy researchers. Ever since the publications of Smith and Glass' (1977) and Luborsky's (1975) meta-analysis documenting the similarities among the contributions of different kinds of therapies to client improvement, attention has been focusing on identifying psychotherapy variables that are shared across different kinds of treatments. While the idea of some "common factors" being responsible for much of the benefit in psychotherapies was discussed before (e.g., Frank, 1961; Rosenzweig, 1936), the emerging empirical evidence that diverse approaches to treatment yielded overall similar benefits provided strong empirical support to the notion of generic or common underlying therapeutic processes.

An additional reason for the increasingly broad acceptance of the alliance concept was the emergence of robust evidence that its quality is reliably correlated with therapy outcome (Horvath \& Symonds, 1991; Martin et al, 2000; Horvath et al, 2011a). While the alliance's relationship with outcome is modest in terms of "explained variance" only about 7\%-, it is, along with therapist effect, the strongest and most reliable link between a therapy process variable and outcome across the universe of treatments and client problems (Wampold, 2001; Horvath et al, 2011b). Importantly, this association with therapy gains appears to be present not only in individual psychotherapy treatments, but equally in helping relationships involving one person caring for another in as diverse contexts as medical care, multi person treatments (families, groups), nursing, and legal assistance (Horvath, Tapia, \& Symonds, 2010). Indeed, there is research evidence suggesting that the quality of the alliance between patient and psychiatrist has accounted for significant amount of variance in psychopharmacological treatments as well (Krupnick et al, 1996).

As a result of this unique history, the concept of alliance stands on its own, without reference to, or dependence on, other constructs or descriptors of the therapy process. This made it possible for therapists with different assumptions about the core therapeutic processes to reach a broad consensus: The quality of the alliance between therapist and client is an 
important element in successful treatments. And, as we noted earlier, over 30 years of subsequent research has indeed empirically validated this proposition (Horvath et al, 2011a). Importantly, this consensus and empirical validation was achieved without a consensual definition of what the alliance is, and how it is linked to other therapy processes. Instead, researchers fitted the general concept into their own theoretical framework, often devising assessment tools that capture their implicit assumptions about what the alliance is in their particular context, but without explicitly differentiating what they measured from other conceptualizations and other measures used in the literature (Horvath, et al., 2011b). Thus, it is the unusual aspect of the alliance construct, as it is used currently, that appears to have a broad common referent which centers around the notion of collaboration with respect to the important elements of the therapy and the idea of enthusiastic participation (Hatcher, 1999), but no clearly articulated consensual definition. In practice, we have a set of overlapping de-facto definitions based on the instruments used to assess the alliance.

\section{The alliance in clinical practice}

\section{Clients' and therapists' unique perspectives of the alliance}

It has been argued that the therapy relationship in general and the alliance in particular has become an explicit part of the therapists' conceptual framework (Castonguay \& Beutler, 2006). It is a component of their professional vocabulary, they are likely to think about their relation to their clients as having relevance to what they are trying to accomplish with the client. In contrast, clients do not normally make use of concepts such as the therapy relationship or the alliance in thinking about their experiences in therapy. However, although clients do not "natively" (without prompting) think of their relation with the therapist in terms of an "alliance", we have evidence that when building blocks of the alliance concepts are introduced to them, and their impressions are queried in the form of questionnaires or inventories, their response to these probes provide very impor- tant clues to the success of the treatment (Horvath \& Hatcher, 2009).

Therefore it seems logically evident that therapist and clients each "observe" the alliance from different perspectives and each of these perspectives yield information relevant to therapy outcome. While the differences in these two perspectives have been empirically well documented (Horvath, Lee, \& Muntigl, 2005) and theoretically discussed (Horvath, Tapia , \& Symonds, 2010), relatively little research has been devoted to the better understanding of which different relational elements therapist and clients are sensitive to when assessing the quality of the alliance.

In order to examine the differences and similarities between therapists' and patients' views of the alliance, we have undertaken a more systematic exploration at how each party experiences this aspect of the therapy process. We are interested in explicating more clearly how each member of the therapy dyad uniquely perceives this phenomenon. The examples that we present are based on five research projects, one implemented in Germany (Krause, 1992a, 1992b), and four in Chile (Altimir et al., 2010; Krause, 2005; Krause \& Cornejo, 1997; Winkler, Avendaño, Krause, \& Soto, 1993). In each of these studies clients and therapists participated in semi-structured interviews where they were asked about their experiences in therapy, including probes about the relationship as well as the change processes and the overall evaluation of change. It is important to note that most of these data are based on open-ended questions. The exploratory and discovery-oriented approach in these projects was chosen because it was the intention of the researchers to get a deeper insight into the phenomenological experience of therapist while they actually worked with clients and likewise source the clients felt experiences during actual therapy sessions. The aim was to encourage the subjects' own elaboration of their responses and descriptions.

\section{Components of the therapeutic alliance}

Affective reciprocity and emotional expressions. Both clients and therapists emphasized the impor- 
tance of an affective bond and its emotional manifestation for the development of a good therapeutic relationship. Clients expected therapist to be gentle, accepting, non aggressive, and not judgmental, warm, and empathic. They expressed the need to feel that the therapist is able to put him or herself (emotionally speaking) in their place. At the beginning of therapy, these therapist characteristics played an important role for the client's choice of therapist and also for the client's decision of whether or not to stay in therapy after the first session. By the same token, clients hoped they would feel a basic positive affect towards the therapist. Such positive affect at start of the therapeutic relationship was taken as a "good sign". The researchers found that many clients tried several different therapists until they found one towards whom they felt affection, and from whom they also got similar feelings. Other clients have abandoned therapy after the first session when they realized that this "reciprocal current of affection" was not present.

Therapists, irrespective of their theoretical orientation, identified the affective quality of the relationship as an important element of a good therapeutic alliance. This includes both what the client feels for the therapist, as well as the feelings the therapist has towards his client. They regarded as important if clients were open to express their own inner experience and emotions, as well as their feelings toward the therapist, such as caring, appreciation and affection. They considered these expressions as markers of a turning point or shift in the therapeutic process towards a more profound and deep level. Likewise, the therapists remarked on their feeling of an emotional bond and/or a special affection for the client as something that was significant for a good alliance. An example of this can be gleaned from a therapist's description of a client:

"...She was a woman who appeared harsh in her way of relating to you...or even a little stiff, and then she showed herself being affective. For me that was very significant...it is the emergence of emotionality in the session that makes you feel something different, after a relationship that was difficult to establish, because she was not a woman who was easy to relate to..."
Acceptance, trust, and understanding. Clients and therapists identified three main aspects that clients must experience from their therapists in order to have a good therapeutic relationship: (a) acceptance, (b) trust, and (c) feeling understood. They felt that these aspects also influence the generation of an affective bond and emotional reciprocity.

Basic acceptance from the professional is often mentioned by clients as a prerequisite for a good relationship. This includes the sense of not being criticized by their therapists. Similarly, therapists in these research projects believed that showing an accepting attitude towards their client, meaning demonstration of respect for him/her as a valid other, and avoiding criticizing or judging was essential. By way of contrast, according to these therapists, if the client felt evaluated or criticized by the therapist, it hindered a good therapeutic alliance. They explained that such stance would result in the client acting submissive towards the therapist, or generate an ongoing misunderstanding between therapist and client, resulting in a lack of cooperation in the therapeutic enterprise. The following description by a therapist exemplifies this sentiment:

"I think that there was an element of submissiveness to an authority there. She would be submissive, trying to do things right, and of course I imagine that must have caused certain resentment, but I think it was not conscious...although I tried to show her that, she would take it almost as a call of attention..."

The therapist's ability to foster a relationship of trust was regarded by clients as crucial for the development of an alliance. Even though clients stated that "you have to put in your part", they felt that it was mainly the therapist's responsibility to be able to generate an initial trust. Sometimes the client's initial reluctance is verbalized as distrust or shame. Other times, when the clients had a higher social status or were older than the therapist, their initial reluctance or hesitancy was expressed in terms of doubt about the therapist's competence. Many of the clients implicitly challenged the therapist to demonstrate his expertise. Ideally, as the alliance gradually developed and strengthened, this initial reluctance was reduced and an increasing degree of confidence was expressed towards the therapist. 
Once this first stage of resistance was overcome, the therapeutic relationship was viewed by the clients as an intimate relationship which, at the same time, was special and different from any other relationship they had. Clients often described it as having a "very special friend", referring to an emotionally charged relationship, in some aspects close to that of friendship, but with two important differences: the therapist was regarded as an expert, and there was an assurance of confidentiality. These two elements underlined the essential asymmetry in the relationship.

Therapists also valued trust as an important relational experience for the client. They believed that the ability to generate trust in the client was predicated on showing an honest, open and genuine attitude towards the client.

Finally, clients considered the sense of being understood by their therapist as an important element throughout all phases of the treatment.

Client: "She was really capturing all the sensations of anxiety, depression... I don't know, all those things. She perceived when I felt rejected or when I felt accepted".

From both the clients' and therapists' perspective, generating these experiences for the client was -initially at least- mainly the therapist's responsibility.

Therapists also highlighted the relevance of the client feeling understood by the therapist, and associated this client perception with the therapist's capacity to be sincere, and being able to show their sensitivity to the client's experiences and needs.

Expertise, commitment, and collaboration. From clients' point of view, the development of the alliance was initially related to perceiving the therapist as an expert. Knowledge was regarded as important professional attribute (along with life experience). Some clients in these studies did not value young professionals: they assumed that a younger person might not have sufficient expertise needed to help solve their problems. On the other hand, therapists highlighted the idea that their clients needed to show commitment both to the therapist as a person, as well as to the therapy. They describe this commitment as the willingness of the client to be helped, to attend therapy, and stay in it, despite the fact that being in therapy and working through their problems may be emotionally painful and difficult:

Therapist: “...I think she was willing to be helped, probably. She was a patient who, despite this disdainful attitude, was hard-working, a fighter, so she was willing to tolerate things that were painful, the anxiety that sessions generate, in order to...she wanted to move forward and recover her autonomy. I think that is a very important issue”...

The clients' implicit and/or explicit collaboration in the work of therapy is something therapists valued and were attentive to. These therapists also emphasized the importance of their own commitment to their clients as an important element of the relationship. They identified the role of this commitment as fostering the client feeling understood, on the one hand, and the trust of the therapist.

Therapist: “...She met someone [referring to the therapist] who could be clear, firm, who could tell her difficult, painful things, but who was not violent, nor aggressive or abusive”....

\section{Evolution of the alliance over phases of treatment}

Clients described the alliance and its components as a phenomenon that develops and changes throughout the process of therapy. In the initial phases of therapy much importance was voiced about the ability to communicate emotions by the therapist and the reciprocal emotional reaction of the client. These exchanges of affective responses were considered indicators of a positive emotional bond. However, clients' disclosure of their own emotions was regarded as important and significant, but the therapist's disclosure of emotions was not highlighted by the clients as important in the early phases of the work.

In subsequent phases of therapy, clients' own emotions come to play a more central role. The quality and benefit of therapeutic transactions are often evaluated on the basis of whether they triggered emotions or not. For example, some clients evaluated the quality of sessions positively if in the session they felt strong emotions. In these cases the more 
mature form of alliance was influenced by the emotional impact of the therapists' intervention to the client:

Client:"It was really a change moment, a milestone in my life, that session... the session destroyed this façade, all those things that I did, to get away from people, unknown to me (...). I had the feeling that she took me to an abyss actually she did not led me to that abyss-, she helped me to take off this façade (...) and then, when I looked at everything I do to keep me away from the people, unintentionally, unconsciously; this being so alert and this bravado that I did, from that moment I started to learn... that people can like me simply because I am me; to some extent it is a banality, but to see it and to feel it and believe it, internalize it - there began the process: just because I am, I am likable - a beautiful message, a wonderful message (laughs softly)-something that I probably never thought really".

Many therapists considered clients' disclosure of affect towards them (therapists) as markers of a turning point or shift in the therapeutic process. The importance clients attributed to the therapist's expertise and experience also varied as treatment moved through the different stages of the therapy process. At the beginning of therapy, this was expressed as the expectation and hope that the therapist's expertise will be instrumental for the solution of the clients' problems. In later phases of the treatment, this sense of the "solution by the therapist" diminished and was replaced by the idea that therapist's expertise will help in the process of (the client's) learning to understand themselves and their problems.

Yet another evolving aspect noted by clients was the change in the asymmetry of the therapeutic relationship as therapy moved through its phases. Towards the end of treatment, some elements of asymmetry between client and therapist lessened as the client reported that they gained expertise, and consequently the distribution of roles and responsibilities between client and therapist shifted:

Client: "Now I interpret my thoughts, etc, everything- well, not everything, but many things, I become aware of relationships, etc., and then I discuss them with Mrs. B and, in general they work out, I mean she generally confirms what I had figured out by myself. That gives me a good feeling ... knowing that I haven't totally forgotten how to reflect, think, that I know how to think properly or correctly about these things, that's a good feeling. That helps, at least it helps me".

\section{Summary of the differences between the clients' and therapists' perspectives}

Clients as well as therapists identified differences between their own contribution and that of the "other." They also noted changes between phases of therapy. Both therapists and clients linked alliance with the therapeutic effects or change that have been achieved in therapy ("little o" outcomes). The most notable differences between therapists and clients related to the clients putting greater emphasis on therapist's expertise and experience - more in the early than in the later stages of treatment- and therapists giving more emphasis on the clients' commitment and collaboration.

From the therapist perspective the alliance was, both a therapeutic tool, a means to foster the therapy process and a "thermometer" indicating the presence of an evolving productive process. Good alliance signaled that therapy is moving along positively. For the client, the alliance was something he or she "felt" and that he/she needed in order to stay in the relationship and to undertake the "hard work" involved in the change process. Both clients and therapists accord major significance to the affective quality of their relationship, but agreement on tasks and goals, as such, was not something either of the participants commented on frequently when they responded to open ended prompts about the important ingredients of a good alliance in therapy.

Although the affective quality of the relationship is something important to both clients and therapists, each of them seemed more attuned to the signs from the other than to their own contributions. This observation was most true for comments on the beginning of the therapy. Commenting on later phases in the process, both therapists and clients assigned more importance to the clients' emotional 
experience of alliance, and how it was closely intertwined with the ongoing change process. For both, aroused client emotions were a sign for the ongoing impacts of therapy, and both are focused on the client's experiences and gains.

Alliance, however, does not have the same conceptual status for clients and therapists. For the former it remains implicit, it "happens" and it is not seen as a vehicle of change, while for the latter, alliance is an explicit element of therapy, it is something to work on and, at least to some extent it is seen as a vehicle or tool for change. Nevertheless each agreed: alliance was the ground on which therapeutic actions materialize and become effective. The effectiveness, in turn, was seen as having a strengthening influence on the alliance. Thus, it seems that, from both perspectives, the relationship between alliance and therapeutic change is a twoway interactive process.

Finally, clients and therapists both identified the importance of being able to generate for the client trust in the therapist; of feeling understood and accepted; and both noted that it is only the client who needs to experience these feelings. This underscores the fact that the alliance is developed and evaluated in the context of an asymmetric relationship in which one is the help-seeker and the other one the help-giver. Nevertheless, clients also noted the value of the increasing shift in some of the roles and responsibilities as treatment progresses. However this "easing of asymmetry" did not imply emotional distance. In fact, clients increasingly valued therapists' emotional expressions towards them and feeling "close" to the therapist throughout therapy.

\section{Conceptual analysis of the core alliance measures}

We have argued earlier that instruments that are used to measure the alliance have taken the place of a conceptual definition of the alliance. In effect, these measures currently embody the meaning of the concept in the research literature (Horvath, 2010a). Therefore we believed that it would be useful to closely examine these instruments to gain a better understanding of the in-practice meaning of the con- cept. In addition, we hoped to gain an insight into how these measures match the therapists' and clients' unique phenomenological experiences we have summarized above. This task was made increasingly difficult however because the burgeoning number of instruments used in the field. In survey of the available alliance measures, Horvath, and colleagues (2011) identified over 38 different instruments used in the study of individual psychotherapy.;. Therefore we chose to focus on the most frequently used "core" measures as recommended by Martin and Elvins (Martin et al., 2000; Elvins \& Green, 2008). These core instruments are ${ }^{2}$ : (1) The California Psychotherapy Alliance Scale (CALPAS; Gaston \& Ring, 1992; Marmar, Weiss, \& Gaston, 1989), (2) the Helping Alliance Questionnaire (HAq-II; Luborsky, 1996) ${ }^{3}$; (3) the Vanderbilt Psychotherapy Process Scales (VPPS/VTAS; Hartley \& Strupp, 1983); and (4) the Working Alliance Inventory (WAI; Horvath \& Geenberg, 1986). These measures accounted for approximately $2 / 3$ of the data included in the latest meta-analysis (Horvath et al, 2011a). Three of these (WAI, CALPAS and HAq-II) are self-report measures and therefore suitable for the purposes of this analysis.

There is an excellent factor analytic study of the underlying factor structure of these three instruments based on clients responses to the WAI, CALPAS and HAq-I, (Hatcher et al., 1996, 1995). The researchers in this study concluded that these three core measures share a central theme conceptualized as "confident collaborative relationship". The analysis we report here is meant to complement this factor analytic investigation by qualitatively analyzing the contents of the instruments at the item level to identify the core concepts the participants are responding to.

We analyzed these measures using the following categories: (1)Voice: From who's perspective is the respondent speaking, (a) first person (the respondent, that is, client or therapist, speaks for him/herself, b) inference about the other (the respondent speaks for the other, e.g., Did you feel that your therapist understood what you hoped to get out of session?), and c) inference about the dyad (the respondent speaks for the therapeutic dyad, e.g., We work on mutually agreed goals); (2) Dimension: To which 
dimension does the item refer to (affective, cognitive or behavioral); (3) Domain: To what domain of experience does the statement refer to (therapy activity, therapeutic relationship, therapy in general, the change process, client's experience, or therapist's experience); and (4) Thematic content: Which of the "traditional alliance dimensions" does the item address: Collaboration, commitment, bond/attachment, trust, acceptance, understanding, or therapist's expertise (see: Table 1).

Two of the authors evaluated each item, and resolved differences in their categorizations as they occurred. The results reported represent a consensual expert rating. The inventories analyzed had different number of items, thus the $\%$ values (indexing the proportion of items in the category) provided in Tables $2 \mathrm{a}-2 \mathrm{~d}$ are discussed in the text.

\section{Differences across measures}

Instruments differ on the emphases they place on sampling the respondent's own voice: (first person "I") versus asking for inferences how the "other" experiences the relationship or the respondent's view of how they are together (see Table 2a). More of the first person voice is solicited in the clients' form than in the therapists' versions but only the clients' version of the CALPAS focus exclusively on the first person perspective. Therapists' instruments rely on inferential judgments between $50 \%$ (WAI) to 90\% (HAq-II) of the items. The CALPAS and the HAq-II sample mostly the therapists' ideas about the client's status (?65\%) while the WAI is more biased toward questions asking the respondents ideas about how they function together as a dyad.

Each of the instruments contain items sampling the dimensions of cognition, affect and behavior, in approximately equal proportions (Table 2b). However, there is a slight bias in favor of the affective dimension in the WAI and toward the behavioral aspects in the therapists' version of the CALPAS.

The thematic domains sampled by each measure showed considerable variation across instruments, but tended to be consistent between versions (clients and therapist's) within each "family" of questionnaires (see Table 2c). The CALPAS "family" focused on therapeutic activity, client's experiences and to a somewhat lesser degree on the therapy relationship per se. The WAI instruments emphasized the change process, therapeutic relationship, therapeutic activity, and the therapist's experience, in this order. The HAq group put a strong emphasis on the theme of the therapist's experience followed by the therapy relationship. Both the clear differences between measures and the consistency within instrument groups suggest that this is the area that most clearly reflects the differences in the test authors' implicit assumptions about what the alliance is "made of." The "therapeutic relationship" itself is -not surprisingly- a strong common theme in each but the WAI is clearly prioritizing the change process, the CALPAS activities and client experiences and the HAq is uniquely interested in the therapist's experiences in client as well as therapist versions.

Our analysis of Thematic Content (Table 2d) most closely approximates the kinds of categories our clinical sample of therapy participants provided. In this analysis a number of interesting similarities within instrument families and differences across instruments emerged once more: Across the bond attachment category, we found strong emphasis in

Table 1. Categories used for the conceptual analysis of the alliance scales

\begin{tabular}{lll}
\hline Voice & Dimension & Domain \\
\hline $\begin{array}{ll}\text { First person } \\
\text { Inference about the other }\end{array}$ & Cognitive & Therapeutic activity \\
Inference about the dyad & Affective & Therapeutic relationship \\
& Behavioral & Change process \\
& & Therapy in general \\
& & Client's experience \\
& & Therapist's experience \\
\end{tabular}


Table 2a. The respondent's perspective

\begin{tabular}{|c|c|c|c|c|c|c|c|c|c|c|c|c|}
\hline & \multicolumn{2}{|c|}{ Calpas-C } & \multicolumn{2}{|c|}{ Calpas-T } & \multicolumn{2}{|c|}{ HAq-C } & \multicolumn{2}{|c|}{ HAq-T } & \multicolumn{2}{|c|}{ WAI-C } & \multicolumn{2}{|c|}{ WAI-T } \\
\hline & $\#$ & $\%$ & $\#$ & $\%$ & $\#$ & $\%$ & $\#$ & $\%$ & \# & $\%$ & $\#$ & $\%$ \\
\hline First person & 24 & 100 & 7 & 23 & 14 & 73.7 & 2 & 10.5 & 25 & 69.4 & 18 & 50 \\
\hline Inference; "other" & 0 & 0 & 19 & 63.4 & 0 & 0 & 13 & 68.4 & 2 & 5.6 & 7 & 19.4 \\
\hline Inference: dyad & 0 & 0 & 4 & 13.3 & 5 & 26 & 4 & 21.1 & 9 & 25 & 11 & 30.6 \\
\hline Total & 24 & 100 & 30 & 100 & 19 & 100 & 19 & 100 & 36 & 100 & 36 & 100 \\
\hline
\end{tabular}

Table 2b. Distribution across the affect, cognition and behavior dimensions

\begin{tabular}{|c|c|c|c|c|c|c|c|c|c|c|c|c|}
\hline & \multicolumn{2}{|c|}{ Calpas-C } & \multicolumn{2}{|c|}{ Calpas-T } & \multicolumn{2}{|c|}{ HAq-C } & \multicolumn{2}{|c|}{ HAq-T } & \multicolumn{2}{|c|}{ WAI-C } & \multicolumn{2}{|c|}{ WAI-T } \\
\hline & \# & $\%$ & $\#$ & $\%$ & \# & $\%$ & \# & $\%$ & \# & $\%$ & $\#$ & $\%$ \\
\hline Cognitive & 9 & 37.5 & 10 & 33.3 & 6 & 31.6 & 6 & 31.6 & 14 & 38.9 & 12 & 33.3 \\
\hline Affective & 7 & 29.2 & 6 & 20 & 7 & 36.8 & 7 & 36.8 & 13 & 31.1 & 14 & 38.9 \\
\hline Behavior & 8 & 33.3 & 14 & 46.7 & 6 & 31.6 & 6 & 31.6 & 9 & 25 & 10 & 27.8 \\
\hline Total & 24 & 100 & 30 & 100 & 19 & 100 & 19 & 100 & 36 & 100 & 36 & 100 \\
\hline
\end{tabular}

Table 2c. Item distribution across Domains

\begin{tabular}{|c|c|c|c|c|c|c|c|c|c|c|c|c|}
\hline & \multicolumn{2}{|c|}{ Calpas-C } & \multicolumn{2}{|c|}{ Calpas-T } & \multicolumn{2}{|c|}{ HAq II-C } & \multicolumn{2}{|c|}{ HAq II-T } & \multicolumn{2}{|c|}{ WAI-C } & \multicolumn{2}{|c|}{ WAI-T } \\
\hline & \# & $\%$ & $\#$ & $\%$ & \# & $\%$ & \# & $\%$ & \# & $\%$ & \# & $\%$ \\
\hline Therapeutic activity & 7 & 29.2 & 9 & 30.0 & 2 & 10.5 & 2 & 10.5 & 6 & 16.7 & 6 & 16.7 \\
\hline Therapeutic relationship & 5 & 20.8 & 5 & 16.7 & 5 & 26.3 & 5 & 26.3 & 7 & 19.4 & 7 & 19.4 \\
\hline Change process & 2 & 8.3 & 2 & 6.7 & 3 & 15.8 & 3 & 15.8 & 9 & 25.0 & 9 & 25.0 \\
\hline Therapy in general & 2 & 8.3 & 3 & 10.0 & 0 & 0.0 & 0 & $\begin{array}{r}1 J .0 \\
0.0\end{array}$ & 4 & 11.1 & 3 & 8.3 \\
\hline Client's experience & 7 & 29.2 & 8 & 23.3 & 3 & 15.8 & 3 & 15.8 & 4 & 11.1 & 4 & 11.1 \\
\hline Therapist's experience & 1 & 4.2 & 4 & 13.3 & 6 & 31.6 & 6 & 31.6 & 6 & 16.7 & 7 & 19.4 \\
\hline
\end{tabular}

Table 2d. Thematic content

\begin{tabular}{|c|c|c|c|c|c|c|c|c|c|c|c|c|}
\hline & \multicolumn{2}{|c|}{ Calpas-C } & \multicolumn{2}{|c|}{ Calpas-T } & \multicolumn{2}{|c|}{ HAq II-C } & \multicolumn{2}{|c|}{ HAq II-T } & \multicolumn{2}{|c|}{ WAI-C } & \multicolumn{2}{|c|}{ WAI-T } \\
\hline & $\#$ & $\%$ & $\#$ & $\%$ & $\#$ & $\%$ & $\#$ & $\%$ & $\#$ & $\%$ & $\#$ & $\%$ \\
\hline Collaboration & 5 & 20.8 & 9 & 30.0 & 7 & 36.8 & 7 & 36.8 & 7 & 19.4 & 8 & 22.2 \\
\hline Commitment & 5 & 20.8 & 10 & 33.3 & 1 & 5.3 & 1 & 5.3 & 3 & 8.3 & 2 & 5.6 \\
\hline Bond attachment & 1 & 4.2 & 1 & 3.3 & 4 & 21.2 & 4 & 21.1 & 6 & 16.7 & 6 & 16.7 \\
\hline Trust & 3 & 12.5 & 2 & 6.7 & 1 & 5.3 & 1 & 5.3 & 3 & 8.3 & 4 & 11.1 \\
\hline Acceptance & 1 & 4.2 & 1 & 3.3 & 0 & 0.0 & 0 & 0.0 & 2 & 5.6 & 2 & 5.6 \\
\hline Understanding & 9 & 37.5 & 5 & 16.7 & 2 & 10.5 & 2 & 10.5 & 13 & 36.1 & 12 & 33.3 \\
\hline Therapist's expertise & 0 & 0.0 & 2 & 6.7 & 4 & 21.1 & 4 & 21.1 & 2 & 5.6 & 2 & 5.6 \\
\hline
\end{tabular}

the HAq-II set and a somewhat lesser one in the WAI measures; however, the CALPAS had only one item (?3-4\%) addressing this issue directly. Collaboration is a significant content in all instruments but more so in the HAq group than the other two. Understanding is a common content in CAL-
PAS and the WAI, but not in the HAq. There are also some features specific to each instrument: CALPAS emphasizes commitment (they explicitly identify a sub-scale associated with this concept) but do not address therapist competence; the HAq instruments on the other hand devote $20 \%$ of the items to the 
competence issue. Acceptance is a relatively low priority in all the measures we analyzed; the HAq in fact does not have a single item targeting this domain.

\section{Differences between client and therapist forms}

One instrument (WAI) very closely "mirrored" the items in the client form and the therapist version. (Even in this case there were a few differences which we will discuss later). Each of the other instruments made substantial content and structure modifications in the two version of the inventory. All the clients' versions emphasized the "first hand" voice of the client. The therapist forms solicited inferences about the "other" or the joint behavior in the majority of items in the CALPAS and the HAq but the WAI split the items evenly between questions targeting direct experience (first person) and inferential probes. With respect to item dimension (cognitive, affective or behavioral), there were minimal differences across versions and the HAq-II and the WAI were also very similar, across client and therapist forms, with respect to item themes. However the CALPAS client instrument highlights the theme of understanding, while the therapist version pays less attention to this theme. As well, the CALPAS therapist form uses twice as many commitment items than its client version.

\section{Summary of the conceptual analysis of the core alliance measures}

The conceptual analysis of the items of three core measures highlighted some differences in the implicit notion of the therapeutic alliance embedded in these instruments. It also became evident that there are substantial differences among these instruments in the way they recognize (or ignore) the unique perspectives of therapists and clients: All measures prompt the respondent to answer from the first person perspective in the client versions, whereas therapist's forms of these instruments tend to ask for inferences about the "other" or the dyad. Although there are slight differences of emphasis, the three measures distribute equally items along the cognitive, affective and behavioral dimensions.

The domain of experience emphasized by each instrument family gives us a glance at the basic differences in the implicit assumptions the authors held about the core ingredients that mark the presence or absence of the alliance is. Thus, the CALPAS focuses predominantly on therapeutic activity and the client's experience of the therapy as meeting their (client's) expectations, while the HAq-II emphasize the therapist's experience in the evaluation of the alliance. Although each measure includes some items directly querying the change process, only the WAI places a special emphasis on it.

The survey of the thematic content of the items provides an additional insight of the latent structure of the alliance each instrument implicitly assumes. Collaboration appears as common theme in all measures. In this our content analysis closely corroborates the factor analytic study of client's responses (Hatcher \& Barends, 1996). Bond/attachment is also sampled by all three measures, but the HAq-II gives a stronger emphasis to this theme than the other two. Meanwhile, the WAI (followed by the CALPAS) pays close attention to the "understanding/being understood" aspect of the alliance. What appears striking is that, in contrast to the participant's perspectives, none of the instruments ask questions about "acceptance/being accepted" aspect of the alliance.

\section{Discussion}

In this paper we made an attempt to clarify the meaning of the concept of alliance as it is perceived in the clinical contexts and as it is implemented in research. To achieve the former objective we summarized existing qualitative research that explored the phenomenological perspectives of clients and therapists; their felt and lived experiences of what was important to them, what did therapeutic alliance meant from the participants' perspective? For our second goal, an understanding of how researchers use the concept of alliance, we did a systematic conceptual analysis of the measures that de-facto define the alliance in empirical research. 
We observed similarities and differences in how the alliance is perceived in clinical contexts and how it is implemented in research. With respect to the different emphasis on "components" of the alliance, we found that the affective components of the alliance were clearly central for the participants (especially the clients). In contrast, the analysis of the questionnaires' content indicated that in the instruments the emotional, cognitive and behavioral aspects of the alliance are equally important.

Agreement on tasks and goals - the more cognitive and behavioral aspects Bordin (1985) has identified as principal indicators of the alliance - were hardly mentioned in response to open ended probes. It seems likely that our respondents recalled and emphasized their immediate, emotionally laden experiences. The participants' recall was more fine grained, whereas the content of the questionnaires reflect a more abstract conceptual framework. These results highlight a dilemma in measuring the alliance: the therapeutic relationship is established and developed at the level of moment to moment interactions, but our theoretical concept of the alliance aims at capturing a more abstract, molar concept, having to do with commitment to the treatment and collaboration between patient and therapist that emerge as a result of the accumulation of these positive moment-to-moment experiences. The questionnaires we use tap into both levels; direct questions about collaboration and commitment and more immediate, affective experiences, but the balance among these elements and levels of abstraction differ across therapist and client versions and across instruments. In measuring the concept one cannot mirror exactly each participants field of experience; there is too much individual variability. But it appears likely that the differences across instruments in terms of the weight given to items tapping into emotion are responsible for the relatively modest overlap across measures. On the other hand it is likely that the more abstract and cognitive items, aimed at collaboration, tap into more of the shared variance across measures.

A notable thematic difference between the participants and the measures perspective was the topic of therapist expertness or competence. This issue was frequently raised by clients but not evident in the measures. There was considerable work done on the impact of social influence in psychotherapy between 1965 and 1980 (e.g., Strong, 1968), but the topic is largely ignored in the current research agenda on the therapy relationship. Perhaps a more careful consideration of the impact of the client's perception of the therapist status is overdue.

In the participants narratives alliance was considered an evolving phenomenon. The emphasis placed on different components changed as the treatment passed through its stages. Luborsky (1976) has pioneered the idea of the evolving role of the alliance and in his first inventory (HAq-I) he has attempted to track the evolution of the alliance. Unfortunately empirical evaluation of the instrument did not confirm this claim (Davis. 2011).

Both therapists and clients incorporated change itself as an integral part of the alliance. A number of researchers believe that it is important to causally differentiate the impact of the alliance (a relationship construct) from changes due to the application of therapy techniques (DeRubies, Brotman \& Gibbons, 2005; Crits-Christoph et al., 2011). While it appears that in carefully conducted studies alliance measures can account for variance in therapy outcome over and beyond what can be accounted for early gains (e.g., Cris-Christoph et al, 2011) the value of this question needs to be more carefully examined. In our view, therapy is a seamless process. For a variety of reasons researchers work hard in identifying discrete components of effective treatments and examine the relation among them to better understand "what works". But these components are only "discrete" in our analyses. It may be unreasonable to search for unidirectional causal arrows among some of the higher level more abstract constructs in psychotherapy. The participants, when asked in open ended interviews, reflected on the qualities of the alliance in relation to the helpfulness of therapy in promoting clients' changes. From the experiential perspective the mutual influence of these aspects of therapy was natural and inevitable.

The qualitative studies highlighted the developmental features of the alliance, its qualities change over the course of therapy. There are also quantita- 
tive studies that corroborate this (e.g., CritsChristoph, et al, 2011, Horvath, 2004). These developments, however, are not reflected in the alliance questionnaires we examined.

If we combine the kinds of information gained from the interviews and the analysis of the measures it suggests that the alliance is an emergent quality of working together productively within an asymmetric relationship. The participants' contributions to the alliance are not parallel or equivalent, but complementary. For example, it is more important for the client to be able to trust the therapist than vice-versa; the responsibility is "structurally" the therapists. Asymmetry implies not only that the two are not "equal" but also that the therapist is obliged to be "there for the client" in a way that the client is not "there for the therapist". In fact, the therapist is obliged not to extract the same emotional benefits (i.e., special friend) that he or she offers to his/her client. Moreover, there is the fact that the therapy is terminal: Unlike friends, the therapist will disappear, with all that he/she has heard and learned about the client in this relationship. For the client it is a relationship where he/she mostly "receives" emotionally, without obligations of reciprocity.

The "core" group of alliance inventories shares the notion of active and joint involvement in the therapy process; our results in this respect closely parallel quantitative investigations (e.g. Hatcher \& Barends, 1996). Our qualitative investigations converge with these quantitative findings, in that beyond this central focus shared across instrument, each rest on different assumptions of what the essential features of a good alliance are. But the qualitative analysis of the measures also revealed that the "voice" of the respondent (self, the other, or we-asa-collective) the instruments "privileged" varies; clients are more often asked to express their own experiences, but greater reliance is used of inferences in therapists' versions. This shift makes intuitive sense in light of the asymmetry of the relationship we discussed earlier, but the degree of inferential versus "direct" voice also varies across instruments.

The relation between these instruments have been investigated quantitatively before (e.g.,
Tichenor \& Hill, 1989; Bachelor, 1991; Cecero et al, 2001) and, in most instances, they found to be significantly correlated -in the statistical sense. But the variance shared among any of these instruments is less than $50 \%$ and usually closer to $20 \%$ (Horvath, $2009 \&$ 2011). Our research has identified some of the ways these instruments differ. Yet each of these different implicit definitions of what the alliance is "made of" reveals an important facet of the complex nature of the relationship in therapy. What is shared across all these instruments it seems to us is the core of the idea of the alliance: a level of partnership and collaboration between therapist and client that emerges and contributes meaningfully to the likelihood of good outcome in therapy. Each alliance measure taps into this core plus something else. The "something else", it seems, comes from the instrument developer's overarching belief or model of how the relationship can be made to "work" in therapy.

\section{Limitations}

There are several limitations to the generalizability of our conclusions. First, our analysis of therapists' and clients' unique phenomenological perspectives is based on samples from Germany and Chile. The nature of this sample offers some benefits (two cultures, diverse languages) but also restricts the generality of the results; different cultural contexts could provide different data. The analysis of the item content was done by two expert raters; however more raters blind to the studies might have resulted in different categorizations.

For the analysis of the contents of the alliance assessment instruments we examined client and therapist rated measures. Observer rated versions of most instruments are also available but we chose not to include them in this study. Our reasons included the consideration of the significant differences in the kinds of judgments required to make the observational ratings and also the fact that observers ratings are often made using segments of sessions rather than the time scale that are reflected in participants judgments. We considered rated alliance a different 
category insofar as what is being judged (i.e., there is no "first voice" report possible) and, in the balance felt best not to compare or contrast them with self-report instrument. On the limitation side, however, the data from these measures will need to be considered to get a full view of the alliance as it is understood in practice.

\section{Conclusions}

As we noted in the introductory paragraph, the concept of the alliance has been embraced with enthusiasm by practitioners and researchers alike. This enthusiasm developed in spite, or possibly because, this concept, notwithstanding its venerable history, has been only broadly described, and agreement on its precise definition has eluded us for over thirty years (see: Psychotherapy, 2006, whole Vol $43 \underline{6}$ ). But the idea of a therapeutic alliance is very much alive; it is used daily by therapists all over the world and there are over 7,000 publications listed in PsycInfo using "Alliance" as one of the keywords. In this project we attempted to shed some light on the meaning of the concept, not by offering another theoretical framework or analysis, but by taking into account the emic perspective and examining what is actually meant by the term where it "lives:" in clinical practice and in the research contexts. We use the term "lives" because we believe that the idea of alliance, though it was germinated in theoretical discourse about different aspects of the therapeutic relationship, has took root, "grew" beyond its theoretical confines in the field, and has many uses in a variety of contexts. The idea of the alliance has evolved past the point where it could be "caged" by a definition. No single definition will satisfy the dynamic cross section of researchers and therapist who harness the utility of this concept. While the polymorphous nature of the alliance has created significant challenges in the research community (Horvath, 2009), it has also served as an umbrella under which researchers with different theoretical orientations could, in unison, focus and validate the critical importance of the quality of the therapy relationship in general, and the complex, by-directional, dynamic, and collaborative nature of all helping processes specifically (Horvath et al, 2010b).

Our attempt to deconstruct or triangulate the alliance concept has highlighted the need to better recognize that clients "live" the therapy relationship, but therapists are not only "in the relationship" but also objectify it to a much greater degree than clients, and make conscious use of it to achieve therapeutic ends. The qualitative analysis we have done underlined these differences and lead us to believe that to refine our understanding of the alliance, therapist, and especially researchers, need to take into account that one will receive qualitatively different "signals" to indicate the status of the alliance from these sources. Our "core" measures are differently attuned to this important distinction but, in general, have not closely adapted to these differences.

In sum, the differences in the participants' phenomenological perspective and the available measures suggest that neither personal recall, nor carefully designed measures, can reflect the full lived experience.

\section{References}

Abend, S. (2000). The Problem of Therapeutic Alliance. In S. T. Levy (Ed.), The Therapeutic Alliance (pp. 1-16). Madison: International Universities Press.

Alexander, L. B. \& Luborsky, L. (1987). The Penn Helping Alliance Scales. In L. S. Greenberg \& W. M. Pinsoff (Eds.), The psychotherapeutic process: A research handbook (pp. 325-356). NewYork: Guilford.

Altimir, C., Krause, M., de la Parra, G., Dagnino, P., Tomicic, A., Valdés, N., Echávarri, O., Vilches, O., Pérez C. (2010). Clients', therapists' and observers' agreement on the amount, temporal location and content of psychotherapeutic change and its relation to outcome. Psychotherapy Research, 20, 472-487.

Baldwin, S. A., Wampold, B. E., \& Imel, Z. E. (2007). Untangling the alliance-outcome correlation: Exploring the relative importance of therapist and patient variability in the alliance. Journal 
of Consulting and Clinical Psychology, 75, 842852.

Bedi, R. P., Davis, M. D., \& Arvay, M. J. (2005). The Client's Perspective on Forming a Counselling Alliance and Implications for Research on Counsellor Training. Canadian Journal of Counselling, 39, 71-85.

Bordin, E. S. (1976). The generalizability of the psychoanalytic concept of the working alliance. Psychotherapy: Theory, Research, Practice and Training, 16, 252-260.

De Rubeis, R. J., Brotman, M. A., \& Gibbons, J. C. (2005). A conceptual and methodological analysisof the nonspecifics argument. Clinical Psychology: Science and Practice, 12, 174-183.

Castonguay, L. G. \& Beutler, L. E. (Eds.). (2006). Principles of therapeutic change that work. New York, NY: Oxford University Press.

Castonguay, L. G., Constantino, M. J., McAleavey, A. A., \& Godfried, M. R. (2010). The alliance in Cognitive-Behavioral Therapy. In Muran, J. C. \& Barber, J. P. (Eds). The therapeutic alliance: An evidence-based guide to practice (pp.150-172). New York, NY: Guilford.

Crits-Christoph, P., Connoly Gibbons, M. B., Hamilton, J., Ring-Kutz, S., \& Gallop, R. (2011). The dependability of Alliance Assessments: The Alliance-Outcome correlation is Larger than you might think. Journal of Consulting and Clinical Psychology, 79, 267-278.

Elvins, R. \& Green, J. (2008). The conceptualization and measurement of therapeutic alliance: An empirical review. Clinical Psychology Review, 28, 1167-1187.

Frank, J. D. (1961). Persuasion and healing. Baltimore: John Hopkins Press.

Greenson, R. R. (1965). The working alliance and the transference neuroses. Psychoanalytic Quarterly, 34, 155-181.

Greenson, R. R. (1967). Technique and practice of psychoanalysis. New York: International University Press.

Hatcher, R. L. (1999). Therapists' view of treatment Alliance and collaboration in therapy. Psychotherapy Research, 9, 405-423.

Hatcher, R. L. (2010). Clinical studies of the therapeutic alliance. In Muran, J. C. \& Barber, J. P.
(Eds). The therapeutic alliance: An evidencebased guide to practice (pp.7-28). New York, NY: Guilford.

Hilsenroth, M. J., Ackerman, S.J., Clemence, A.J., Strassle, C.G., \& Handler, L. (2002). Effects of structured clinician training on patient and therapist perspectives of alliance early in psychotherapy. Psychotherapy: Theory/Research/Practice/ Training, 39, 309-323.

Horvath, A. O. (2004). Sources of clients' appraisal of the alliance: An exploratory investigation of unique interpretations and consensually shared observations. Presented at the American Psychological Association Conference. Honolulu, Hawaii.

Horvath, A. O. (2009). How real is the "real relationship"? Psychotherapy Research, 19, 273-277.

Horvath, A. O. (2009, Oct.). Conceptual and methodological challenges in alliance research: Is it time for a change. Paper presented at the European Society for Psychotherapy Research Conference. Bolzano, Italy.

Horvath, A. O. (2010a, June). Do we need a shared theory of therapy relationship: "A cost benefit analysis". Paper presented at the Society for Psychotherapy Research Conference. Asilomar, CA.

Horvath, A. O. (2010b, July). Research on the therapeutic relationship: History, findings and future directions. Paper presented at the Israeli Science Foundation: Multiple Lenses on the Therapeutic Relationship Conference. Jerusalem.

Horvath, A. O. (2011). The complex world of alliance assessments: Will the real alliance please stand up? Paper presented at the Society for Psychotherapy Research Conference. Bern Switzerland.

Horvath, A. O., Del Re, A. C., Flückiger, C., \& Symonds, D. (2011a). The alliance in adult psychotherapy. Psychotherapy: Theory, Research, Practice, Training, 48, 9-16.

Horvath, A. O., Del Re, A. C., Flückiger, C., \& Symonds, B. D. (2011b). The alliance. In J. C. Norcross (Eds.). Relationships that work (2ed.). New York, NY: Oxford University Press.

Horvath, A. O. \& Greenberg, L. S. (1986). Development of the working alliance Inventory. 
In L. S. Greenberg \& W. M. Pinsof (Eds.), The psychotherapeutic process: A research handbook (pp. 529-556). New York: Guilford.

Horvath, A. O., Lee, E., \& Muntigl, P. (2005, December). The therapeutic relations in cross cultural counseling: Building and maintaining the therapeutic alliance across cultures. Poster presented at the 11th International Counseling Conference. Bangkok, Thailand.

Horvath, A. O. \& Luborsky, L. (1993). The role of the therapeutic alliance in psychotherapy. Journal of Consulting and Clinical Psychology, 61, 561-573.

Horvath, A. O. \& Symonds, B. D. (1991). Relation between working alliance and outcome in psychotherapy: A meta-analysis. Journal of Counseling Psychology, 38, 139-149.

Horvath, A. O. \& Hatcher, R. (2009, August). Two viewpoints on the Future dirrections for Alliance Theory. Paper presented at the American Psychological Association Conference. Toronto, Canada.

Horvath, A. O., Tapia, L., \& Symonds, D. B. (2010). The alliance in couple therapy: The web of relationships. In J. C. Muran \& J. P. Barber (Eds.), The therapeutic Alliance: An Evidence-Based Approach to Practice (pp. 210-239). New York: Guilford.

Krause, M. (1992a). Erfahrungen mit Beratung und Therapie -Veränderungsprozesse aus der Sicht von KlientInnen. [Experiences with consultation and therapy-Change processes from the viewpoint of clients]. Freiburg: Lambertus.

Krause, M. (1992b). Efectos subjetivos de la ayuda psicológica-Discusión teórica y presentación de un estudio empírico. Psykhe, 1, 41-52.

Krause, M. (2005). Psicoterapia y cambio. [Psychotherapy and Change]. Santiago de Chile: Ediciones Universidad Católica.

Krause, M. \& Cornejo, M. (1997). Psicoterapia y Percepción de Cambios: Su expresión en metáforas. [Psychotherapy and perception of changes: Its expression in metaphors]. Terapia Psicológica, 6, 83-91.

Krupnick, J. L., Sotsky, S. M., Simmens, S., Moyer, J., Elkin, I., Watkins, J., et al. (1996). The role of the therapeutic alliance in psychotherapy and pharmacotherapy outcome: Findings in the
National Institute of Mental Health Treatment of Depression Collaborative Research Program. Journal of Consulting and Clinical Psychology, 64, 532-539.

Luborsky, L. (1976). Helping alliances in psychotherapy. In J. L. Cleghhorn (Ed.), Successful psychotherapy (pp. 92-116). New York: Brunner/Mazel.

Luborsky, L., Singer, B., \& Luborsky, L. (1975). Comparative studies of psychotherapies; "Is it true that everybody has won and all must have prizes"? Archives of General Psychiatry, 32, 9951008.

Luborsky, L., Barber, J. P., Siqueland, L., Johnson, S., Najavits, L. M., Frank, A., et al. (1996). The revised Helping Alliance Questionnaire (HAq-II). The Journal of Psychotherapy Practice and Research, 5, 260-270

Martin, D. J., Garske, J. P., \& Davis, K. M. (2000). Relation of the therapeutic alliance with outcome and other variables: A meta analytic review. Journal of Consulting and Clinical Psychology, 68, 438-450.

Muran, J. C. \& Barber, J. P. (2010). The therapeutic alliance: An evidence-based guide to practice. New York, NY: Guilford.

Rosenzweig, S. (1936). Some implicit common factors in diverse methods of psychotherapy. American Journal of Orthopsychiatry, 6, 412-415.

Safran, J. D. \& Muran, J. C. (2006). Has the Concept of the Therapeutic Alliance Outlived Its Usefulness? Psychotherapy: Theory, Research, Practice, Training, 43, 286-291.

Samstag, L. W. (Ed) (2006). Special issue Working alliance in psychotherapy. Whole. Psychotherapy: Theory, Research, Practice, Training, 43.

Smith, M. L. \& Glass, G. V. (1977). Meta-analysis of psychotherapy outcome studies. American Psychologist, 32, 752-760.

Stone, L. (1961). The Psychoanalytic Situation: An Examination of Its Development and Essential nature. New York: International Universities Press.

Strong, S. R. (1968). Counseling: An interpersonal influence process. Journal of Counseling Psychology, 15, 215-224.

Wampold, B. E. (2001). The Great Psychotherapy Debate. Mahwah NJ: Erlbaum. 
Winkler, M. I., Avendaño, C., Krause, M., \& Soto, A. (1993). El cambio psicológico desde la perspectiva de los consultantes. [Subjective effects of the psychological aid-Theoretical discussion and presentation of an empirical study]. Terapia Psicológica, 20, 7-19.

Zetzel, E. R. (1956). Current concepts of transference. International Journal of Psychoanalysis, 37, 369-37.

\section{Authors Note}

We gratefully acknowledge the funding of the German Academic
Exchange Service (DAAD) and the Chilean National Fund for Science and Technology, projects $N^{\circ} 1930700,1030482,1060768,1080136$.

\section{Notes}

\begin{abstract}
${ }^{1}$ For an exception see: Bedi, Davis, \& Arvay, 2005.
${ }^{2}$ Each of these instruments have been adapted to fit specific needs and applications; many exist in "short" versions, and some that were originally designed as a questionnaire were made to serve as an observer's rating instrument. We have studied the original questionnaire forms.

${ }^{3}$ There are two versions of this instrument. The original (HAq: Alexander \& Luborsky, 1987) -which exists in several versions- was extensively revised (HAq-II: Luborsky et al., 1996). We analyzed the revised version.
\end{abstract}

Artículo recibido: 15/06/2011

Revisión recibida: 21/07/2011

Aceptado: 14/09/2011 